\title{
BLOOD GAS MEASUREMENTS IN CLINICAL PRACTICE
}

\author{
E. J. M. CampbelL, M.D., M.R.C.P. \\ Assistant, The Professorial Medical Unit, The Middlesex Hospital, London, W.I
}

UNTIL recent years methods of blood gas measurement have been difficult and they were therefore not widely available. Their possible value in routine clinical practice was consequently largely unknown and unexplored, and many clinicians have forgotten their basic knowledge of oxygen and carbon dioxide physiology.

The sequence is now in reverse. There are easy methods which could be widely available. Clinicians are learning their value in practice and in the process are relearning respiratory physiology. The aim of this article is to catalyse this chain reaction by indicating the most practicable methods and by describing the use of the measurements in practice.

There is now no need for physicians to rely entirely on clinical judgment in assessing, for example, methods of treating respiratory depression in cases of poisoning. They would be unhappy without measurements of blood sugar in diabetic coma, urea in renal failure or sodium in adrenal failure. They are now entitled to require knowledge of the $\mathrm{PCO}_{2}$ in respiratory failure.

\section{Blood Collection for Gas Analysis}

This presents the first difficulty which has distinguished blood gas measurements from other biochemical investigations. The exchanges of oxygen and carbon dioxide between blood and tissues prevent samples taken from the antecubital veins in the usual manner from having much value. Venous blood can be used for the estimation of carbon dioxide content (see below) and even, with special precautions, for the estimation of carbon dioxide tension $\left(\mathrm{PCO}_{2}\right)$ and $\mathrm{pH}$ (Brooks and Wynn, 1959), but arterial blood is preferable for these and, of course, essential for meaningful estimates of oxygen. Arterial puncture continues to be viewed askance partly because of alleged difficulty and partly because of fear of damage. Like all clinical procedures, arterial puncture is best learned by example and after half a dozen successful attempts one is almost as good as the most expert. A syringe lubricated by heparin $(5,000$ units $/ \mathrm{ml}$.) should be used with heparin filling the deadspace of nozzle and needle. Mercury is unnecessary. The blood should be allowed to fill the syringe under its own pressure; it should not be drawn by suction because this is liable to introduce bubbles of air. The period of sampling should be between one and two minutes and the patient should be relaxed and breathing naturally to ensure that the sample reflects steady-state conditions as far as possible. Temporary fluctuations in the breathing may otherwise cause the state of the arterial blood gases to be unrepresentative. After withdrawal, the site of puncture should be compressed sufficiently firmly to obliterate the distal pulse for at least five minutes.

Discomfort or complications following competent arterial sampling are unrecorded. I have been told of damage to the median nerve in the course of a 'search' for the brachial artery by an inexperienced person, and I have known an alarming hæmatoma to develop in a confused patient who was allowed to flex the elbow repeatedly while an indwelling arterial needle was in place. There can be few clinical procedures that are free from such hazards. I have not heard or read of any other serious complications following arterial puncture in the total experience of several workers amounting to over 25,000 punctures.

\section{Storage and Transport of Arterial Blood Samples}

The overriding consideration in the care of blood samples is that they be kept out of contact with the air. Measurements of $\mathrm{Po}_{2}, \mathrm{PCO}_{2}$ and $\mathrm{pH}$ must usually be made within a few minutes of collection so the blood is most conveniently kept in the syringe. Neither cooling nor the addition of fluoride is satisfactory in preventing the metabolism of the cells. Early analysis of blood kept in the syringe is the best arrangement.

These considerations do not apply to blood to be analysed for carbon dioxide content which is not seriously affected by the metabolism of the cells nor by minor degrees of contact with the air. Blood for carbon dioxide content can be transferred to tubes (by ' filling from the bottom'), which should be completely filled and then stoppered. Blood for oxygen content or saturation presents an intermediate problem. Analysis can be deferred up to an hour or so (depending on the accuracy required) if the blood is cooled. Such blood is preferably and conveniently kept in the 
syringe. If it is transferred to another container greater care is required than for carbon dioxide content and the transfer should be anærobic.

\section{Methods}

Under this heading I propose to review the practicability of the various available methods bearing in mind cost, technical skill, time and reliability.

\section{Blood Oxygen}

(I) Content and Saturation. For accuracy, reliability and cheapness the Van Slyke method (Van Slyke and Neill, 1924) remains supreme. Unfortunately, it requires more skill and time than most routine biochemical techniques, so other methods should be considered if the number of analyses is large or the analyst's time is precious. For large numbers one of the many spectrophotometric or reflectrometric methods is probably best and can be set up at reasonable cost (Refsum and Hisdal, 1958; Verel, Saynor and Kesteven, 1960).

(2) Tension. Until recently the only practicable method for measuring blood oxygen tension was the microtonometric or 'bubble' method of Riley (Riley, Campbell and Shepard, 1957). The apparatus is inexpensive, but each analysis requires about 40 minutes of skill and concentration. It should soon be replaced by the polarographic methods (e.g. Severinghaus and Bradley, I958; Bishop, 1960), which promise to be sufficiently inexpensive, reliable and rapid for routine use.

\section{External Oximetry}

Spectrophotometric techniques for the estimation of the arterial oxygen saturation in vivo (Nilsson, 1960) are unfortunately not very accurate with respect to absolute values, but can be used to follow changes (see Campbell and Dickinson, I960, p. 120). The instruments are still moderately expensive and temperamental.

\section{Carbon Dioxide}

(I) Content. As in the case of oxygen, the Van Slyke method is the most accurate and the cheapest. The analysis for carbon dioxide content is less laborious than that for oxygen, so the demands on time and skill are not so great. Nevertheless, automatic chemical analysers promise to replace the Van Slyke method in busy laboratories.

(2) Tension. Until recently there have been only two practicable methods for the measurement of blood carbon dioxide tension. First, the 'direct' microtonometric bubble method of Riley, and secondly, the 'indirect' method in which $\mathrm{PCO}_{2}$ is calculated from the $\mathrm{pH}$ and carbon dioxide content. Both methods require time, skill and attention far above that generally available in routine laboratories; although with improvements in $\mathrm{pH}$ meters this statement is becoming less true.

With the development of more stable and reliable $\mathrm{pH}$ meters two further methods of estimating blood $\mathrm{PcO}_{2}$ have been introduced. First, the $\stackrel{5}{?}$ interpolation method of Astrup (1956) and, secondly, the titration electrode method of Severinghaus and Bradley (1958). These have brought $\mathrm{PCO}_{2}$ measurements within the reach of routine laboratories, although the skill required is still above that demanded by most routine chemical procedures.

The Rebreathing Method for Estimating Mixed Venous and Arterial Carbon Dioxide Tension. Collier's (1956) introduction of the rebreathing method for estimating blood carbon dioxide tension is the greatest practical advance in clinical respiratory physiology of the last 20 or 30 years. This method abolishes all analytical problems of $\mathrm{PcO}_{2}$ estimation. Using a rapid continuous carbon dioxide gas analyser, the method is extremely simple. Without this instrument it is still, given slightly greater understanding, possible to apply the method using simple and cheap equipment (Campbell and Howell, r960). The whole procedure, including preparation and analysis occupies Io minutes.

\section{Practical Conclusions}

All general hospitals should today be able to provide facilities for the following methods:

(I) Arterial oxygen saturation by the Van Slyke method.

(2) Mixed venous carbon dioxide tension by the rebreathing method.

(3) Blood carbon dioxide content by the Van Slyke method.

With these and an understanding of the underlying physiology the clinician can evaluate any disturbance of blood gas regulation. With particular reference to respiratory disease, the possession of a recording spirometer in addition to the above enables the vast majority of respiratory problems to be adequately assessed.

Supplementation of these four essentials should be governed by the particular interests to be served.

\section{Physiological Principles Underlying Clinical Interpretation}

Like most laboratory measurements, values for blood gas concentrations cannot be interpreted clinically without appreciation of the biological factors affecting them. An adequate exposition of the physiology of the blood gases is far beyond the scope of this article, but there are certain im- 


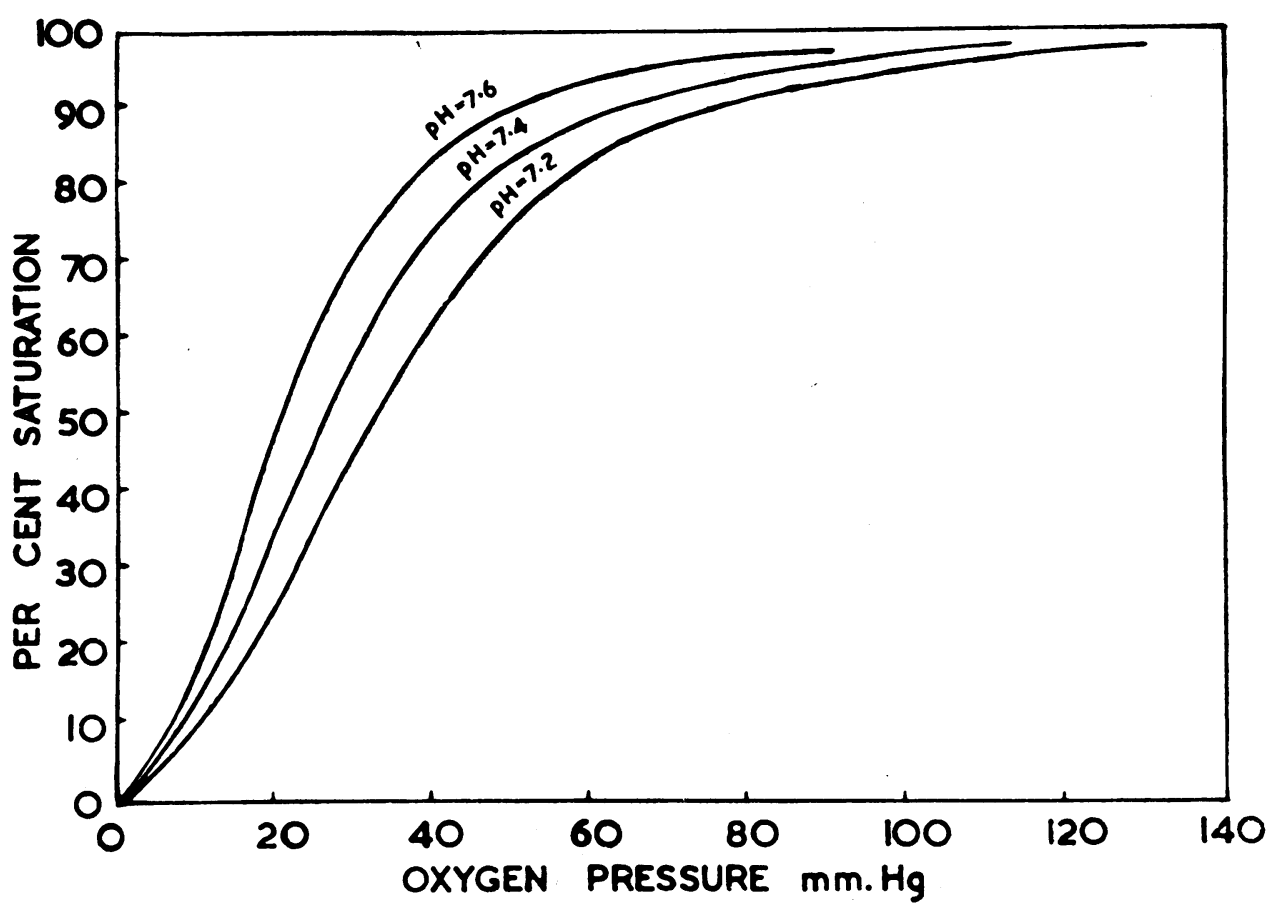

FIg. 1.-Oxygen dissociation curve of blood.

portant principles which deserve mention because of their practical significance.

\section{Oxygen}

The relationship between oxygen saturation and tension is given by the dissociation curve (Fig. $\mathbf{I}$ ). The normal arterial tension is about $90 \mathrm{~mm} . \mathrm{Hg}$, giving a saturation of about $97 \%$. The shape of the dissociation curve is such that the saturation of arterial blood does not fall below $90 \%$ until the tension falls below $60 \mathrm{~mm}$. $\mathrm{Hg}$, whereas further reduction in tension causes increasingly severe desaturation. The practical implications of this relationship are: firstly, that respiratory function has to be seriously disordered before measurements of saturation become unequivocally abnormal; secondly, when the saturation falls below $90 \%$ it becomes so sensitive to small changes in tension that variations in breathing and bodily activity cause the saturation to vary considerably, making isolated measurements unreliable indications of the average level. These facts partly explain the eagerness with which methods of continuous or frequent oxygen tension determinations are being developed.

Exercise increases oxygen consumption, increases the flow of blood through the lungs and causes the blood entering the lungs to have a lower saturation. These changes all tend to increase the oxygen tension difference between the alveolar air and the pulmonary capillary blood and thus to reduce arterial oxygen tension. When this falls below $60 \mathrm{~mm}$. $\mathrm{Hg}$, the saturation falls rapidly. Hence, in a subject whose resting saturation is over $90 \%$, exercise can be used to stress respiratory function and the amount of exercise (as judged by the oxygen uptake) required to cause the arterial saturation to fall below $85-90 \%$ provides a useful method of detecting and assessing many types of disorder. In lung diseases it is an excellent substitute for measurements of diffusing capacity to which it is in some ways superior and which it can be used to calculate (Shepard, 1958).

\section{Carbon Dioxide}

Interpretation of changes in blood carbon dioxide depends upon appreciation of two relationships:

(I) Arterial carbon dioxide tension is governed by the ratio of carbon dioxide production to effective, i.e. alveolar, ventilation:

Arterial $\mathrm{PCO}_{2}=$

$\frac{\mathrm{CO}_{2} \text { production }}{\text { alveolar ventilation }} \times$ barometric pressure

If alveolar ventilation is halved, arterial $\mathrm{PCO}_{2}$ is doubled and vice versa.

(2) The proportion of carbon dioxide in the 


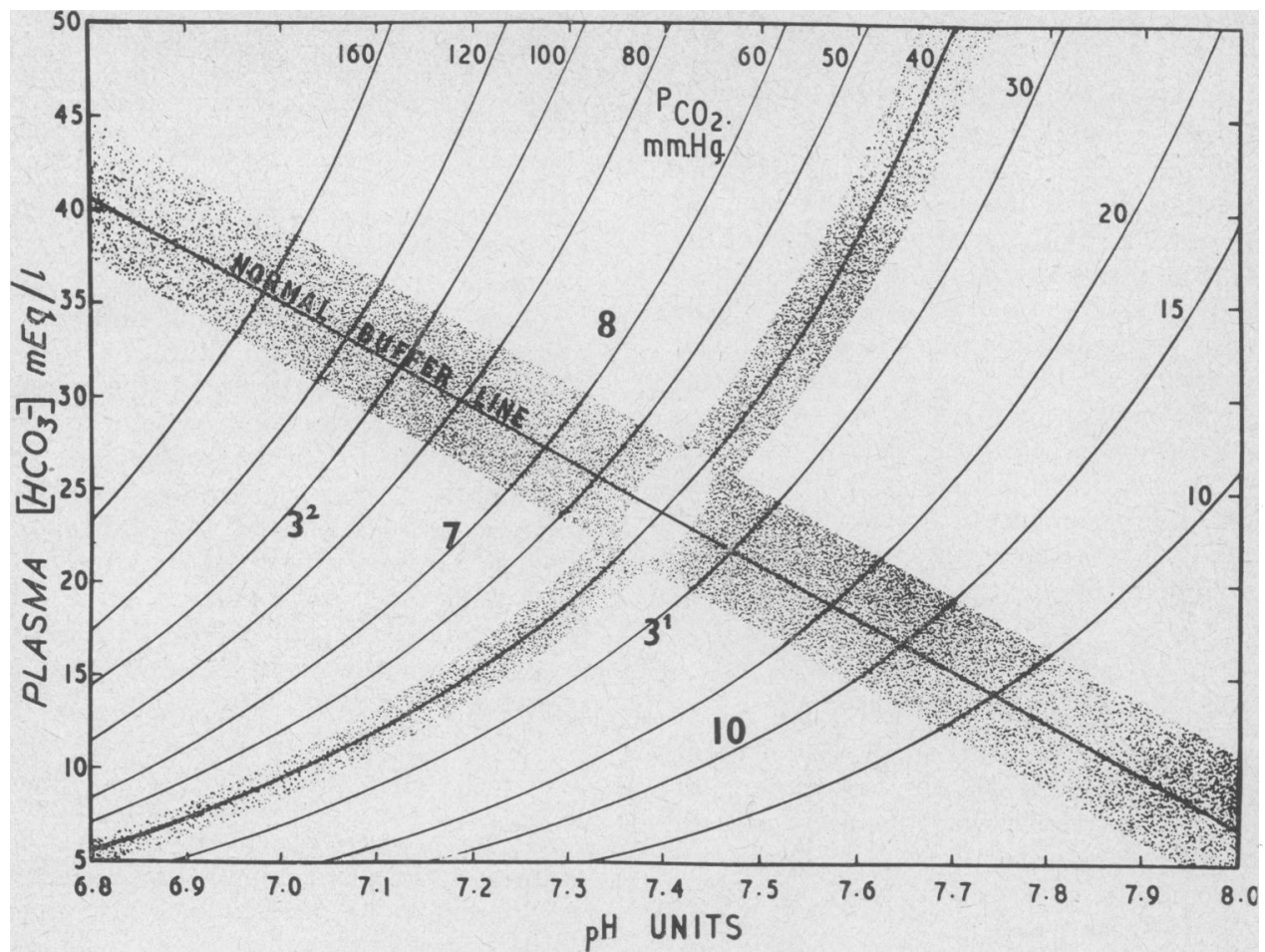

Fig. 2.-Bicarbonate/pH diagram. The numbers refer to the cases described in the text.

form of dissolved carbon dioxide, the proportion in the form of bicarbonate and the $\mathrm{pH}$ are interdependent. This interdependence is expressed in the Henderson-Hasselbalch equation:

$$
\mathrm{pH}=\mathrm{pk}^{\prime}+\log : \frac{\text { bicarbonate concentration }}{\mathrm{CO}_{2} \text { concentration }}
$$

As the concentration of dissolved carbon dioxide is a constant function of the partial pressure of carbon dioxide, the equation can be written:

$$
\mathrm{pH}=\mathrm{pk}^{\prime}+\log . \frac{\text { bicarbonate concentration }}{0.03 \times \mathrm{PCO}_{2}}
$$

This equation enables the third variable to be calculated from knowledge of the other two. This is valuable technically and also important clinically because it shows that the full effects of a disturbance of any one of the three depends upon the other two. This is illustrated by Cases $3,7,8$ and Io described later.

There are several ways of expressing the Henderson-Hasselbalch relationship graphically, of which one of the most popular is the bicarbonate: $\mathrm{pH}$ diagram (Fig. 2). Its use is indicated by the case histories.

\section{Clinical Value}

Some overall judgments are required before describing the illustrative cases if these are to be seen in true perspective.

\section{Arterial Oxygen Measurements}

(None of the following remarks can necessarily be applied to cases with intracardiac shunts which present special problems.) It is still uncertain how valuable arterial oxygen measurements are or would be outside special cardiopulmonary units. They have been essential to the elucidation of the functional disturbance in many diseases, but evidence is still lacking about their value in the management of the individual patient. This view can be elaborated under three headings.

(I) Diagnosis. Cases in which a measurement of arterial oxygen saturation is essential to the diagnosis are very uncommon. The use of such manœuvres as exercise and/or varying the oxygen concentration of the inspired air to supplement clinical and radiological evidence will enable a diagnosis to be reached on nearly all occasions. Cases I and 2 described below may seem to be exceptions to this general rule, but, in fact, the diagnosis in both was strongly suspected and could have been made by other methods. The diagnosis in the patient with polycythæmia (Case 5) depended on the estimation of $\mathrm{PCO}_{2}$ rather than on the oxygen saturation.

(2) Prognosis. Evidence is still scanty that measurements of arterial oxygenation add much to the assessment of prognosis in either acute or 
chronic respiratory disease (Cotes, 1960). Such evidence must await the introduction of adequate methods for assessing the variability of arterial oxygenation.

(3) Treatment. If anoxic anoxia is suspected during an acute illness, the inspired air can and should be enriched with oxygen. If anæmic or stagnant anoxia is suspected during an acute illness the inspired air should be $100 \%$ oxygen. These decisions can be made clinically without recourse to measurements of blood oxygenation. Paradoxically, the oxygen concentration to give a patient is better judged from the arterial or mixed venous $\mathrm{PCO}_{2}$ (see Case 4 below). In patients suffering from chronic anoxia the value of oxygen can be adequately judged on clinical grounds, particularly by observing the effects on exercise tolerance.

\section{Blood Carbon Dioxide Measurements}

Measurements of blood carbon dioxide content are, of course, essential to the assessment of metabolic (i.e. non-respiratory) disorders of acid base metabolism (e.g. Cases 8, Io and II) and are required for the full assessment of respiratory disturbances (e.g. Cases 3 and 7).

Estimations of arterial or mixed venous $\mathrm{PCO}_{2}$ are of great clinical value and provide information which often cannot be obtained by other methods. The management of Cases 6, 9 and 1 I was particularly helped by having such facilities immediately and continuously available.

There is no substitute for measurements of $\mathrm{PCO}_{2}$ when the adequacy of ventilation is in doubt. Anyone who attempts to forecast the adequacy of ventilation on the basis of clinical evidence finds that he is very often wrong. Furthermore, although there are other measurements which may help, none of them is as simple as the rebreathing method for estimating $\mathrm{PCO}_{2}$.

In metabolic disturbances of hydrogen ion regulation the $\mathrm{PCO}_{2}$ is valuable in combination with the blood carbon dioxide content in providing an estimate of the $\mathrm{pH}$. This topic is further discussed elsewhere in this issue (Ashby and Campbell, 196r).

\section{Illustrative Cases}

It has been easy to recollect patients in whom measurements of $\mathrm{PCO}_{2}$ were of great value and radically affected the management. It has been difficult to think of cases in which measurements of arterial oxygen saturation were important, although many could be found in which the measurement was interesting and added to rather than changed the picture.
CASE 1.-Differentiation of Cardiac and Respiratory Cause of Breathlessness. A woman of 25 had had severe kyphoscoliosis since childhood. In the preceding few $\frac{}{\Phi}$ months she had become increasingly breathless and $\varrho$ blue on exertion. The heart was enlarged and there $C$ was a widely split second sound in the pulmonary area. $\Rightarrow$ The arterial saturation at rest breathing air was $72 \%, \stackrel{\bar{S}}{+}$ and while breathing $100 \%$ oxygen it was $86 \%$. The $\overline{0}$ $\mathrm{PCO}_{2}$ was normal.

\section{Comment}

These figures illustrate the difficulty of interpretation of changes in saturation in this range. The patient's colour changed unequivocally from blue to pink on receiving oxygen, an observation $\vec{\circ}$ which had led to the belief that her. anoxia was $\overrightarrow{\vec{H}}$ pulmonary in origin. In fact, she had a true $\stackrel{\sigma}{\sigma}$ venous-arterial shunt and the findings are explic- $\bar{D}$ able as follows: firstly, at a saturation of $72 \% 3$. cyanosis is easily seen, whereas at $86 \%$ it may be undetectable. Secondly, the data breathing air. suggested that there was a shunt equal to 50 to $70 \%$ 䓌 of the cardiac output. This implies that 30 to $50 \%$ of the blood traversed the lungs, where, while breathing $100 \%$ oxygen, it could take up $2 \mathrm{ml}$./ $100 \mathrm{ml}$. extra oxygen in solution. This would be sufficient to account for an increase in arterial saturation of about $10 \%$. The remaining $4 \%$ would readily be attributable to overcoming the 'distribution' effect of her chest deformits $\vec{\theta}$ which, while breathing air, probably caused the o blood flowing through parts of her lungs to be inadequately oxygenated.

None of this difficulty would have arisen if $30 \%$ oxygen had been used instead of $100 \%$ (see Case 2 ).

Subsequently this patient was found to have an atrial septal defect and progressive pulmonary hypertension, causing a ' reversed ' shunt.

CASE 2.-Acute Cerebral Disease and a Localized Pulmonary Lesion. A woman of 53 developed an acute neurological illness with evidence of a focal cerebral lesion and meningeal irritation. The cerebro-spinal fluid contained many polymorphs but no organisms. The differential diagnosis included meningitis, brain abscess and cerebral tumour. X-ray of the chest showed a lobulated shadow in the left lower lobe with prominent vascular connection. Arterial blood was sampled while the patient was breathing $30 \%$ oxygen and was found to have an oxygen saturation of $85 \%$.

\section{Comment}

Arterial unsaturation while breathing 30\% oxygen can only be due to anatomical venous- ज arterial shunt. (Desaturation due to generalized $N$ lung disease is corrected by $30 \%$ oxygen.) This finding provided the lynch-pin of the diagnosis of pulmonary arterio-venous fistula, a condition known to predispose to meningo-encephalitis. Investigation for cerebral tumour was therefore not pursued. The patient recovered.

CASE 3.-Combined Respiratory and Metabolic Disorder in Emergency Surgery. A neurotic woman of 38 
was admitted with suspected peritonitis of four days' duration and physical signs of congestion or pneumonia of the lower lobes. There was clinical evidence of dehydration, sodium depletion, hyperventilation and arterial desaturation. The arterial blood (Fig. 2, point $\left.3^{1}\right) \mathrm{PCO}_{2}$ was $26 \mathrm{~mm} . \mathrm{Hg}$; plasma carbon dioxide content was I9.I mM./1.; pH 7.40; oxygen saturation was $87 \%$.

Exploratory laparotomy showed retroperitoneal hæmorrhages and œdema but no ruptured viscus. The operation, which took one hour, had just finished when the heart stopped. After cardiac massage through a thoracotomy, the heart started beating normally.

Arterial blood taken at this time had a pH of 7.00 and a $\mathrm{PCO}_{2}$ of $90 \mathrm{~mm} . \mathrm{Hg}$ (Fig. 2, point $3^{2}$ ). Shortly afterwards the heart stopped again and she died. Autopsy showed the intestine to contain large quantities of broken glass which she had apparently swallowed.

\section{Comment}

The pre-operative findings for $\mathrm{pH}, \mathrm{PCO}_{2}$ and carbon dioxide content were similar to those in the patient with salicylate poisoning (Case ro) in that there was a combined metabolic acidosis and respiratory alkalosis with a normal $\mathrm{pH}$. The metabolic acidosis was probably in part due to the electrolyte disturbance caused by her abdominal condition, but may have been partly due to the respiratory alkalosis. That the respiratory alkalosis was not simply a consequence of the metabolic acidosis, but was probably due to the anoxia caused by the pneumonia, is indicated by the high normal $\mathrm{pH}$.

The combination of a low arterial $\mathrm{PCO}_{2}$ and a low arterial oxygen saturation is the pattern of blood gas changes seen in conditions causing maldistribution of pulmonary blood flow. The data indicate that over $40 \%$ of the blood flowing through this patient's lungs was ' shunted', i.e. exchanged no oxygen or carbon dioxide. The consequent arterial hypoxia causes hyperventilation which blows off carbon dioxide from the relatively normal parts of the lungs, but cannot correct the hypoxia.

The combination of a high alveolar ventilation and maldistribution of pulmonary blood flow almost certainly means that this patient required a very large total ventilation. This she obviously did not receive during the operation because an arterial $\mathrm{PCO}_{2}$ of $90 \mathrm{~mm}$. $\mathrm{Hg}$ can only be reached by fairly prolonged underventilation. The effects of such a respiritory acidosis on the $\mathrm{pH}$ was greatly aggravated by the pre-existing metabolic acidosis (see Fig. 2).

It may be suggested that this patient presented a hopeless case, but if such patients are to be saved greater attention must be paid to respiratory function and less absolute reliance placed on clinical judgment. The anæsthetist thought he had overventilated this patient. In fact, the cardiac arrest may well have been attributable to underventilation.

CASE 4.-Management of Anoxia in Respiratory Failure. A man of 55 with severe chronic obstructive lung disease was admitted with pneumonia. He was slightly confused and there was central cyanosis. The arterial $\mathrm{PCO}_{2}$ was $8 \mathrm{I} \mathrm{mm} . \mathrm{Hg}$ and the oxygen saturation was $44 \%$. He was given $34 \%$ oxygen to breathe which increased the saturation to $82.5 \%$ but caused him to become semi-comatose due to underventilation and aggravation of the respiratory acidosis-the $\mathrm{PCO}_{2}$ rose to $99 \mathrm{~mm} . \mathrm{Hg}$. Reduction of the inspired oxygen concentration to $28 \%$ improved his mental state and the $\mathrm{PCO}_{2}$ fell to $86.5 \mathrm{~mm} . \mathrm{Hg}$. with restoration of some anoxic drive to his ventilation as the saturation fell to $66 \%$. The inspired oxygen concentration was subsequently gradually increased without ill effect.

\section{Comment}

This case illustrates the paradox that knowledge of the $\mathrm{PCO}_{2}$ is more helpful than knowledge of the oxygen saturation in managing the treatment of anoxia in such a patient. He clearly had to receive oxygen. The question was: how much? The answer is: as much as can be tolerated without allowing severe respiratory depression as indicated by a serious increase in the $\mathrm{PCO}_{2}$.

CASE 5.-Polycythamia. An obese man of 46 was found to have polycythæmia (Hb. $18 \mathrm{~g} . / 100 \mathrm{ml}$.). His dusky colour was attributed to a combination of the polycythæmia and a colourful racial origin. After a time, however, the presence of undue cyanosis was appreciated and the arterial oxygen saturation was found to be about $50 \%$. A cardiac cause was excluded and he was referred for pulmonary function studies as a suspected case of chronic lung disease. His ventilatory capacity as judged by spirometry was found to be normal but the arterial $\mathrm{PCO}_{2}$ was $85 \mathrm{~mm} . \mathrm{Hg}$.

\section{Comment}

The combination of underventilation in the presence of normal ventilatory capacity is diagnostic of the syndrome of primary underventilation (Burwell, Robin, Whaley and Bickelman, I956), which is usually accompanied by polycythæmia and obesity. (I am indebted to Dr. J. B. L. Howell for the description of this case.)

CASE 6.-Failure to Breathe Post-operatively. A woman of 33 was operated on for a subphrenic abscess. The exposure was difficult and the anæsthetist maintained controlled ventilation with the patient fully paralysed by curare. After operation the patient would not breathe. The possibility of carbon dioxide retention was considered and the artificial ventilation given more vigorously but the blood pressure fell. The mixed venous $\mathrm{PCO}_{2}$ was estimated by the rebreathing method and found to be about $150 \mathrm{~mm} . \mathrm{Hg}$. Overventilation was therefore given with greater confidence and the $\mathrm{PCO}_{2}$ maintained at about $70 \mathrm{~mm} . \mathrm{Hg}$. The patient began to breathe and recovered completely.

\section{Comment}

The patient's toxæmia and the various drugs used in the course of anæsthesia had made any 
reliance on 'signs of carbon dioxide retention' unjustifiable. The anæsthetist did not know whether the patient was being over- or underventilated.

Anybody who measures $\mathrm{PcO}_{2}$ in 'complicated' cases who are ' not doing well ' after operation can report similar experiences (see also. Cases 3 and 7).

CASE 7.-Distress After Thoracotomy, Cardiac Bypass and Aortic Surgery. A man of 21 had his aortic stenosis relieved with the aid of hypothermia and cardiac by-pass. In the immediate post-operative period his condition was satisfactory, but after three hours it began to deteriorate. He was distressed and breathless with rapid shallow breathing and had an increasing tachycardia. The mixed venous $\mathrm{PcO}_{2}$ was estimated by the rebreathing method and found to be $68 \mathrm{~mm} . \mathrm{Hg}$, corresponding to an arterial $\mathrm{PCO}_{2}$ of about 62. Assisted ventilation was not tolerated so tracheostomy was performed. His condition immediately improved and his $\mathrm{PCO}_{2}$ fell to about 40 .

\section{Comment}

An arterial $\mathrm{PCO}_{2}$ of $62 \mathrm{~mm} . \mathrm{Hg}$ is not dangerous, but the plasma bicarbonate concentration was later reported to have been $22 \mathrm{mEq} / \mathrm{l}$. at the time of his deterioration. This is apparently a 'normal 'value, but when considered in conjunction with the $\mathrm{PCO}_{2}$ (Fig. 2, point 7) it can be seen to represent a significant metabolic acidosis, being well below the normal range of the bicarbonate buffer line. Thus the patient had both a respiratory and a metabolic acidosis giving a severe acidæmia $(\mathrm{pH}$ 7.19) and improvement in ventilation was therefore doubly important.

CASE 8.-Resistant 'Heart Failure'. A woman of 60 had gross odema presumed to be due to ischæmic heart disease although the history and ECG were equivocal. Initially she responded well to mercurial diuretics, but odema recurred and the plasma 'alkali reserve' was found to be $33 \mathrm{mEq}$./1. Although the plasma potassium concentration was normal she was thought to be suffering from metabolic alkalosis secondary to potassium depletion caused by overuse of the mercurial diuretics. The arterial $\mathrm{pH}$ was found to be 7.3 I, implying a $\mathrm{PcO}_{2}$ of about $65 \mathrm{~mm} . \mathrm{Hg}$ (Fig. 2, point 8). A review of the case showed that she was, in fact, suffering from severe obstructive lung disease.

\section{Comment}

Patients who develop ' cor pulmonale' almost always have carbon dioxide retention. This empirìcal observation, whatever its explanation (Campbell and Short, 1960), can provide a useful aid to diagnosis in 'heart failure' of uncertain cause.

CASE 9.-Barbiturate Poisoning. An unconscious woman of 33 was admitted one Sunday evening. She had swallowed an apparently large amount of cyclobarbitone early in the day. Her respiration rate was $8 / \mathrm{min}$. and she was considered by most observers to be very blue. Preparations were made for the administration of a stimulant drug and the arterial $\mathbf{P C O}_{2}$ was measured so that the effects of this drug could be documented. The $\mathrm{PCO}_{2}$ was found to be $32 \mathrm{~mm} . \mathrm{Hg}$. No drug was given and the patient woke up eight hours later.

\section{Comment}

Now that easy methods of $\mathrm{PCO}_{2}$ estimation are available, comparisons of methods of treating respiratory depression should become more convincing.

CASE 10.-Salicylate Poisoning. A woman of 52 swallowed $25 \mathrm{~g}$. of aspirin and was admitted to hospital two days later with oliguria. There was obvious hyperventilation. The plasma bicarbonate concentration was $13 \mathrm{mEq} / \mathrm{l}$. and the arterial $\mathrm{PCO}_{2} 17 \mathrm{~mm} . \mathrm{Hg}$, giving a calculated $\mathrm{pH}$ of 7.46. The blood urea was $255 \mathrm{mg}$./100 ml. and the plasma salicylate concentration was $55 \mathrm{mg} . / 100 \mathrm{ml}$. A diuresis began shortly after admission. She was treated conservatively with water and electrolyte replenishment governed by her urinary losses and weight changes. Her blood urea, bicarbonate, $\mathrm{PCO}_{2}$ and $\mathrm{pH}$ were little changed two days later, but subsequently she recovered rapidly.

\section{Comment}

At the time of the measurements this patient still had the respiratory alkalosis characteristic of the early stages of salicylate intoxication (Singer, 1954). She also was in severe metabolic acidosis, which may have been due either to the salicylate poisoning or the renal failure. The resultant was $\$$ slight alkalæmia. Correction of the respirator alkalosis by the administration of carbon dioxide or by reducing ventilation would have caused fairly severe acidæmia; correction of the metabolic acidosis by the administration of alkali would have caused a severe alkalæmia. Either of these steps might have been unfortunate in such an ill patient. This case, therefore, illustrates the importance of a full evaluation of acid-base disturbances. (This case has been fully described elsewhere: Campbell and MacLaurin, 1958.)

CASE I I.-Renal Asthma. This case, described elsewhere (Ashby and Campbell, r96r) (p. 43), illustrates many points, the most important lesson for routine practice probably being the value of a simple method of estimating $\mathrm{PCO}_{2}$ in supporting a clinical impression which, by itself, carried little conviction. The diagnosis of bronchial asthma had the blessing of six doctors who had seen the patient previously. The possibility that it was wrong and the patient was really overbreathing was not taken sufficiently seriously to justify spending time on arterial blood analyses in the middle of a busy day. In fact, the first reading of a very low mixed venous $\mathrm{PCO}_{2}$ was disbelieved, but the simplicity of the method allowed it to be checked in ten minutes.

\section{Summary}

(I) Practical problems and methods of blood gas analysis are discussed.

(2) Some physiological principles underlying clinical interpretation are emphasized. 
(3) Eleven illustrative cases are described.

\section{Acknowledgments}

I am grateful to Professor A. Kekwick, Dr.
J. D. N. Nabarro, Mr. T. Holmes-Sellors and Mr. L. P. Le Quesne for permission to describe these cases and to Mr. M. Hobsley, F.R.C.S., and Dr. J. B. L. Howell for reading the manuscript.

\section{REFERENCES}

Ashby, R. R., and Campbell, E. J. M. (1961): A Case of Renal Asthma, Postgrad. med. F., 37, 43.

AstruP, P. (1956): A Simple Electrometric Technique for the Determination of Carbon Dioxide Tension in Blood and Plasma, Total Content of Carbon Dioxide in Plasma, and Bicarbonate Content in 'Separated ' Plasma at a Fixed Carbon Dioxide Tension (40 mm.Hg), Scand. F. clin. Lab. Invest., 8, 33.

Bishop, J. M. (1960):-Measurement of Blood Oxygen Tension, Proc. roy. Soc. Med., 53, 177.

Brooks, D., and WynN, V. (1959): Use of Venous Blood for pH and Carbon Dioxide Studies, Lancet, i, 227.

Burwell, C. S., Robin, E. D., Whaley, R. D., and Bickelman, A. G. (1956): Extreme Obesity Associated with Alveolar Hypoventilation-a Pickwickian Syndrome, Amer. F. Med., 2I, 8I I.

Campbell, E. J. M., and Dickinson, C. J. (1960): Clinical Physiology, p. r20. Oxford: Blackwells.

- and Howell, J. B. L. (1960): Simple Rapid Methods of Estimating Arterial and Mixed Venous $\mathrm{PCO}_{2}$, Brit . med. $\mathcal{F} ., \mathrm{i}, 45^{8}$.

—_, and MACLAURIN, R. E. (1958): Acute Renal Failure in Salicylate Poisoning, Ibid., i, 503.

, and SHORT, D. S. (1960): The Cause of CEdema in 'Cor Pulmonale', Lancet, i, I 184.

Collier, C. R. (1956): Determination of Mixed Venous Carbon Dioxide Tensions by Rebreathing, F. appl. Physiol., 9, 25.

CotES, J. E. (1960): Respiratory Function and Portable Oxygen Therapy in Chronic Non-specific Lung Disease in Relation to Prognosis, Thorax, 15, 244.

Nilsson, N. J. (1960): Oximetry, Physiol. Rev., 40, I.

Refsum, H. E., and Hisdal, B. (1958): Construction and Use of a Simple Reflectometer for Determination of Hæmoglobin Oxygen Saturation in Blood, Scand. F. clin. Lab. Invest., ro, 439.

Riley, R. L., Campbell, E. J. M., and Shepard, R. H. (1957): A Bubble Method for Estimation of $\mathrm{PCO}_{2}$ and $\mathrm{Po}_{2}$ in Whole Blood, Y. appl. Physiol., Ir, 245.

Severinghaus, J. W., and Bradeey, A. F. (I958): Electrodes for Blood $\mathrm{Po}_{2}$ and $\mathrm{PcO}_{2}$ Determination, Ibid., $13,515$.

SHEPARD, R. H. (1958): Effect of Pulmonary Diffusing Capacity on Exercise Tolerance, Ibid., r2, 487.

SINGER, R. B. (1954): The Acid-base Disturbance in Salicylate Intoxication, Medicine (Baltimore), $33, \mathbf{~}$.

VAN SLYKe, D. D., and NeILl, J. M. (1924): The Determination of Gases in Blood and other Solutions by Vacuum Extraction and Manometric Measurement (I), f. biol. Chem., 6r, 523.

Verel, D., SAynor, R., and Kesteven, A. B. (1960): A Spectrophotometric Method of Estimating Blood Oxygen Using the Unicam SP 600, $\mathcal{F}$. clin. Path., 13, 36r.

\section{EXTRA BIBLIOGRAPHY}

Davenport, H. W. (1958): The ABC of Acid-base Chemistry, 4th ed. Chicago: University of Chicago Press.

Moller, B. (1959): The Hydrogen Ion Concentration in Arterial Blood, Acta med. scand., 165, supp. 348.

Woolmer, R. F. (1959): pH and Blood Gas Measurement. A Ciba Foundation Symposium. London: J. \& A. Churchill. 